\title{
Chaprer 7
}

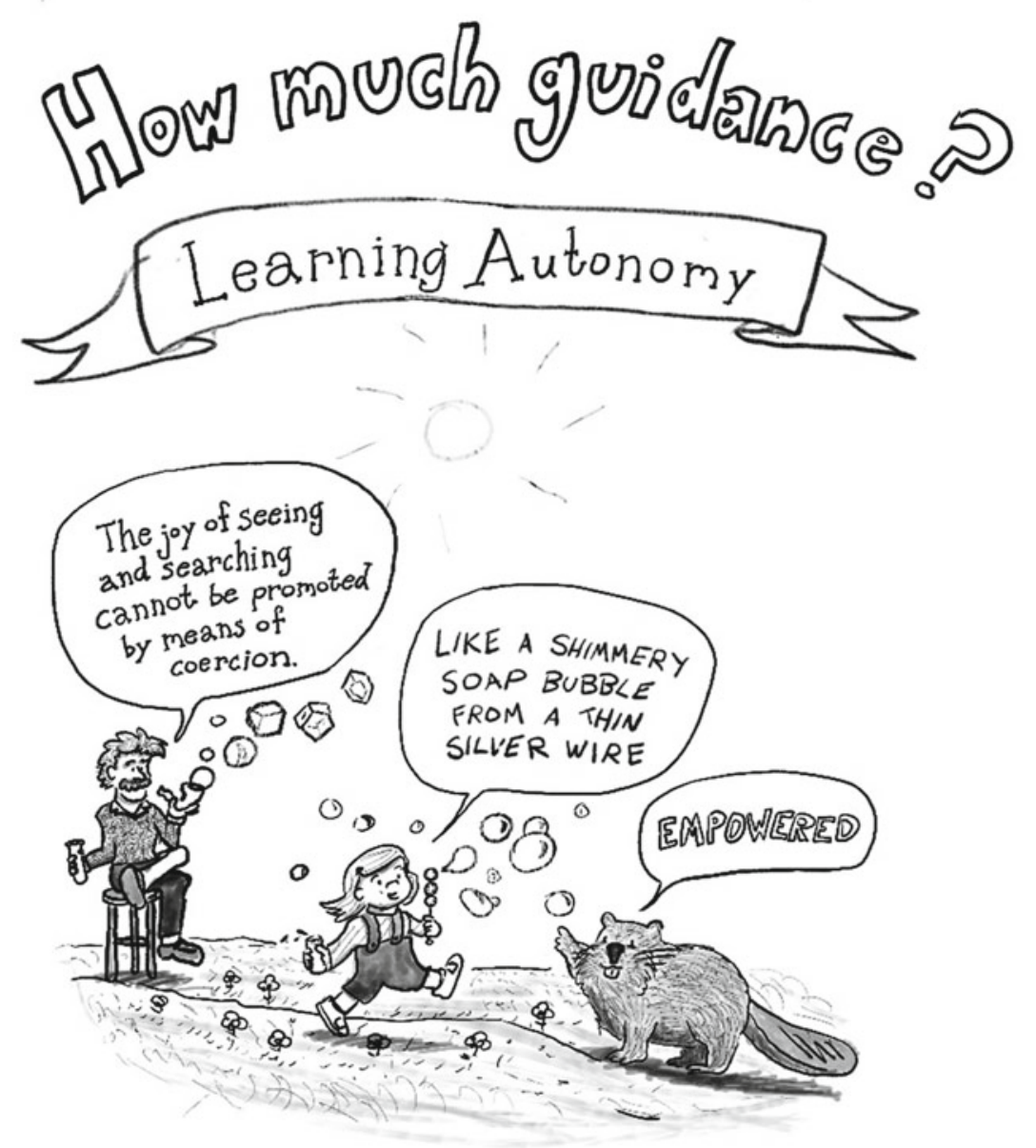




\section{Chapter 7 \\ How Much Guidance?}

One great piece of feedback on the MELT, written on a post-it note during a workshop introducing the models, was 'obvious'. That terse slight in many ways reflected that which the MELT was intended to convey: what educators do when they facilitate learning effectively. It is common that an educator looks at a version of MELT and says 'this is what I'm already doing!' That is perfect, for MELT provides an articulation of what educators often do implicitly and makes it explicit. For the person who said 'obvious', the question is whether their teaching approach is as obvious to their students or colleagues as it is to them. The answer is probably 'no'.

Educators use MELT for guidance when they perceive a need to move from leaving understanding implicit to making it explicit, in order to

(1) improve their awareness of their own practice and its connection to theory;

(2) enhance student metacognition, especially students' regulation of their own learning;

(3) connect disparate teaching energies, practices, sectors and theories.

As noted in earlier chapters, learning autonomy in MELT is not a characteristic that increases linearly, but a relationship: between students, between students and teachers, and between students and concepts. Engaged teachers attend implicitly to learning autonomy, because it is fundamental to ownership of the learning enterprise. MELT supports an explicit exploration of learning autonomy.

\subsection{Autonomy: Engaged Learning, Engaged Teaching}

A lot was made in the previous chapters about the continuum of learning autonomy. Chapter 2 discussed the continuum in relation to students and Chaps. 4 and 5 discussed it in relation to theory and action research. To reiterate here, autonomy in MELT is not an attribute to be attained to or an optimum level of guidance. A continuum suggests that there is a broad spectrum of possibilities, where all parts of the continuum are vital for learning: there is nothing inherently superior about initiate on 
this continuum, nor is there anything implicitly lesser about emulate. The important thing is to ask frequently, 'how much guidance do these students need?' Autonomy in MELT depends on the relationship between learners and what is learned, where it is learned and who it is learned with. Learning autonomy distinctly ebbs and flows in a tidal zone, moving from low autonomy to high autonomy and back.

Measuring or pinning down learning autonomy is awkward, because it is a messy and recursive concept... Yet autonomy is absolutely central to daily teaching and learning. Because learning autonomy is a 'relationship term' in MELT, not an absolute quality, students don't become autonomous. Rather, they operate at times with higher levels of autonomy, depending on their familiarity with context and the rigour needed in the situation, and they frequently cycle back to lower levels of autonomy in less familiar contexts. This is what we found with employed graduates, who shuttle back and forth between different levels of autonomy in employment, showing that autonomy is non-linear and context-specific [2]. If MELT helps educators understand how much learning autonomy is required by a student, that 'measurement' can make a lot of sense for those who know and understand the context and inform teaching practices in practical ways. However, to say ' $\mathrm{x} \%$ of students were working with high levels of autonomy' does not communicate anything meaningful to those without knowledge of the context.

In practical ways, MELT promotes constructive alignment to engineer quality, engaged learning. For example, MELT can inspire cognitive and affective learning outcomes or goals (Chap. 1), inform the design of face-to-face, online and blended learning environments (Chap. 3), inform the assessment of learning (Chap. 3) and help structure evaluative elements of course effectiveness (Chap. 5). However, constructive alignment only comes to life through the efforts of engaged teachers, for it requires teacher care and empowerment to realistically engage learners.

The MELT are used in a variety of ways for teaching, learning and researching, and this necessarily includes the assessment of student learning. Crucially, the continuum of learning autonomy suggests a student move from reliance on the teacher for feedback towards self-assessment, and back again in fresh contexts. Assessment rubrics, each informed by the six facets of MELT but with performance criteria made specific to a task, provide something in common between assignments. Such rubrics also provide something specific to that task alone. MELT rubrics straddle the middle ground between rubrics that are too specific to allow students to generalise their learning from it [3] and those that are too general and therefore provide little guidance. Importantly, when students use teacher feedback from one assignment to improve a subsequent assignment, the connections between assignments due to MELT make a substantial difference [4]. As students calibrate to teacher expectations using MELT-informed rubrics, they become more realistic in their self-assessment according to the rubric, and more able to give useful feedback to peers [5]. As shown in Chap. 3, an effective technique is to allocate marks to students' response to peer feedback, as well as marks for the feedback they give to others, as opposed to students allocating marks to students.

While this book has emphasised learning autonomy, teachers themselves need to model different levels of autonomy. Autonomy and ownership is a crucial dimension 
for teachers, because the MELT only work when educators make the models their own. If we want students to become increasingly autonomous and take risks in learning, then teachers themselves must have a license to act autonomously, at times, in order to show students what autonomy looks like. There is a need, then, to consider factors that increase or decrease teacher autonomy, because this implicitly affects teacher engagement and effectiveness.

When teachers do not show initiative or willingness to improvise, this may speak to the nature of the systems they teach in. This nature is often determined by what learning institutions reward and what the consequences of non-compliance are. Curriculum developers and policymakers should consider factors that mediate for and against teacher autonomy and ownership, including curriculum and quality assurance processes created for course, program and institution level.

MELT's facets articulated along the continuum of learning autonomy provide a framing that is 'sufficiently well structured' and 'sufficiently nebulous', as an educator said [6]. Another educator likened MELT to a thin silver wire providing the structure in which shimmery soap bubbles can emerge [7]. As the MELT draws on 100 years of educational research and practice, it contains nothing of a surprise in its separate elements. Rather, it is the juxtaposition of the facets with the levels of learning autonomy that makes the MELT distinctive in structure. But it is the educators who care, and their students, who make the MELT fluid through human interactions.

Overall, the MELT help to:

1. Envisage connections by providing a conceptualisation that holds in tension disparate educational practitioners', administrators, communities and researchers' perspectives.

2. Join together separate disciplinary and transdisciplinary usage.

3. Map the educational landscape, because they are informed by numerous educational theories, conceptual frameworks and practices.

4. Spiral through education and become a thinking routine, from primary school to Ph.D. level.

5. Delineate learning autonomy, unpacking how much guidance learners and teachers need.

6. Differentiate the curriculum, where the consideration of autonomy promotes an understanding of how to manage the curriculum for gifted and talented students, students with learning disabilities, and the full range of 'average' students.

7. Couple cognitive and affective learning, foregrounding the relationship between these domains

8. Prompt ethical, social and culturally minded teaching and learning.

9. Pose seven probing questions to teachers and students that are key across all educational contexts.

10. Materialise in audience-dependent ways, where educators adapt and articulate their own MELT, fit to the context and audience, even as the nature of the six facets and of the continuum of learning autonomy are maintained. 
11. Engage teachers by absolutely relying on their professional sense of identity and care as they use their own adaptations of MELT to engage learners in the development of sophisticated thinking.

The four contemporary issues this book addressed were the following:

- Enabling educators to help students think in sophisticated ways.

- Connecting different aspects of education so that they mutually reinforce and complement each other.

- Deepening educators' understanding of the dimensions of student autonomy in learning.

- Engaging with educational theory in ways that make practical sense to educators.

How much guidance do educators need to so enable, connect, deepen, and engage? The answer is in your hands.

\subsection{Conclusion: Structure Provided, Creativity Needed}

The characteristics of MELT are based on 100 years of education research and mirror 100,000 years of human learning as experienced by 100 billion Homo sapiens. The next billion brains born from 2023 to 2030 need something different to those which have already been born. Existing members of our species brought us to the amazing creativity, adaptability, and problem-solving that will enable, in all likelihood, a human population of 8 billion alive in 2023. However, despite the massive problemsolving endeavour of our species, we are facing the catastrophic consequences of our solutions.

We need some guidance towards a mode of learning that will help the next billion brains, at the very least, to do no further damage to our world. We need to earn the name sapiens. MELT provides this guidance in a conceptual manner, but this guidance should not be represented as a set of rules or mandates. The MELT's adaptable structure absolutely requires the breath of creativity to bring it to life in particular subjects, disciplines and contexts. The MELT are fully dependent on Homo sapiens' willingness to adapt, to heat solid structures with the warmth of human interaction until conversations become fluid, and then crystallise in new shapes for student learning. If there are any things that are unique about the MELT, these include the articulation of the facets of sophisticated thinking along the continuum of learning autonomy, and the consequent way the models are able to simply connect theories with theories and theories with practice. The MELT's shared questions are effective prompts to engage teaching and learning. They continuously ask teachers and students, 'What will we use? What do we trust? How do we arrange? What does it mean? How do we relate? How much guidance?' and especially, 'What is our purpose?'

Melting, flowing, shaping and crystallising need to happen time and again, so that each of the MELT suits its context and is renewed when there are changes in that context. Each adapted MELT model interlinks conceptually with all other MELTs, 
and can help teachers and students make the connection across education's years, subjects, ideologies, and contexts. The MELT provide the adaptive fluidity we need to conceptualise the coherent and connected learning journey needed for the billion brains born from 2023. The children of Kevin, Shelly and Tara could be beneficiaries of an adept use of MELT, enabling them to experience and perceive their own forest of engaged learning. If those billion brains experience a coherent and connected curriculum, they may become sophisticated thinkers who craft solutions that first cause no harm. As they become the generation to lead us globally, they could pull us back from inevitable, accelerating, planetary degradation so that we all may enjoy a more evitable Earth trajectory. Remaining endangered habitats may be preserved despite increased human population and polar ice might remain frozen, because education, early childhood to Ph.D. is fluidly connected with the MELT.

\section{References}

1. Einstein Bubble in Cartoon: Einstein, A. (2010). The ultimate quotable Einstein. Princeton, NJ: Princeton University Press.

2. Willison, J., Sabir, F., \& Thomas, J. (2017). Shifting dimensions of autonomy in students' research and employment. Higher Education Research \& Development, 36(2), 430-443.

3. Adcroft, A. (2011). The mythology of feedback. Higher Education Research \& Development, 30(4), 405-419.

4. Willison, J. (2012). When academics integrate research skill development in the curriculum. Higher Education Research and Development, 31(6), 905-919.

5. Wu, C., Chanda, E., \& Willison, J. (2014). Implementation and outcomes of online self and peer assessment on group based honours research projects. Assessment \& Evaluation in Higher Education, 39(1), 21-37.

6. Willison, J., \& Buisman Pijlman, F. (2016). Ph.D. prepared: Research skill development across the undergraduate years. International Journal of Researcher Development, 7(1), 63-83.

7. Wisker, G. (2018). Frameworks and freedoms: Supervising research learning and the undergraduate dissertation. Journal of University Teaching and Learning Practice, 15(4), 2.

Open Access This chapter is licensed under the terms of the Creative Commons Attribution 4.0 International License (http://creativecommons.org/licenses/by/4.0/), which permits use, sharing, adaptation, distribution and reproduction in any medium or format, as long as you give appropriate credit to the original author(s) and the source, provide a link to the Creative Commons license and indicate if changes were made.

The images or other third party material in this chapter are included in the chapter's Creative Commons license, unless indicated otherwise in a credit line to the material. If material is not included in the chapter's Creative Commons license and your intended use is not permitted by statutory regulation or exceeds the permitted use, you will need to obtain permission directly from the copyright holder.

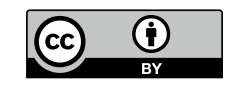

